\title{
IDENTIFIKASI SAMPAH ANORGANIK PADA EKOSISTEM MANGROVE DESA TALAWAAN BAJO KECAMATAN WORI KABUPATEN MINAHASA UTARA
}

\author{
Muhammad Ghibran Kahar ${ }^{1}$, Joshian N.W.Schaduw ${ }^{1}$, Natalie D.C.Rumampuk ${ }^{1}$, Wilmy E.Pelle ${ }^{1}$, \\ Calvyn Sondakh ${ }^{1}$, Jeannete F.Pangemanan².
}

1. Program Studi IImu Kelautan Fakultas Perikanan dan IImu Kelautan, Universitas Sam Ratulangi Manado

2. Program Studi Agrobisnis Perikanan Fakultas Perikanan dan Ilmu Kelautan, Universitas Sam Ratulangi Manado

*e-mail : Kahargibran@gmail.com

\begin{abstract}
Abstrack
Mangrove ecosystem is a place where all pollutants come from which carry various kinds of pollutants originating from the mainland. The sea is also a direct disposal site by human or industrial activities in an easy way, as we know that there is organic and inorganic waste. The purpose of this research is to identify the type of inorganic waste and calculate the amount of inorganic waste density in the mangrove ecosystem of Talawaan Bajo Village. The method used in this study is the transect line. The results showed that the dominant inorganic waste in the mangrove ecosystem of Talawaan Bajo Village was predominantly plastic waste with a total of $132 \mathrm{pot} / 900 \mathrm{~m}^{2}(1.466 \mathrm{Pot} / \mathrm{Ha})$ with a weight of $3131,55 \mathrm{gram} / 900 \mathrm{~m}^{2}(34.795 \mathrm{~g} / \mathrm{ha})$. The results of this study will be a recommendation for the local government to make an appeal and socialization about the dangers of inorganic waste to the life of the ecosystem in the sea and education about the management of inorganic waste especially plastic types to the public properly.
\end{abstract}

Keywords: Mangrove, Inorganic Waste, Talawaan Bajo

\begin{abstract}
Abstrak
Ekosistem mangrove merupakan tempat bermuaranya seluruh bahan pencemar yang membawa berbagai macam bahan pencemar yang berasal dari daratan. Laut juga merupakaan tempat pembuangan langsung oleh kegiatan manusia atau industri dengan cara yang mudah, seperti yang kita ketahui bahwa terdapat sampah organik dan anorganik. Adapun tujuan penelitian ini yaitu untuk mengidentifikasi jenis sampah anorganik dan menghitung jumlah kepadatan sampah anorganik di ekosistem mangrove Desa Talawaan Bajo.Metode yang dipakai pada penelitian ini adalah line transek. Hasil penelitian menunjukan bahwa sampah anorganik yang ada di ekosistem mangrove Desa Talawaan Bajo dominannya adalah sampah jenis plastik dengan total total 132 pot $/ 900 \mathrm{~m}^{2}(1.466$ $\mathrm{Pot} / \mathrm{Ha})$ dengan berat total $3131,55 \mathrm{gram} / 900 \mathrm{~m}^{2}(34.795 \mathrm{Gram} / \mathrm{Ha})$. Hasil penelitian ini akan menjadi bahan rekomendasi ke pemerintah daerah untuk membuat himbauan dan sosialisasi tentang bahaya sampah anorganik terhadap kehidupan ekositem di laut serta edukasi tentang pengelolaan sampah anorganik khusunya jenis plastik ke masyarakat dengan baik.
\end{abstract}

Kata Kunci : Mangrove, Sampah Anorganik, Talawaan Bajo 


\section{PENDAHULUAN}

Ekositem Mangrove merupakan tempat bermuaranya seluruh bahan pencemar yang membawa berbagai macam bahan pencemar yang berasal dari daratan. Laut juga merupakan tempat pembuangan langsung oleh kegiatan manusia atau industri dengan cara yang murah. Oleh karena itu, pada ekosistem mangrove akan mudah dijumpai berbagai jenis bahan pencemar yang berasal dari kegiatan industri (Siahainenia, 2001). Bahan pencemar di antaranya adalah sampah organik dan sampah anorganik, dimana sampah anorganik

Menurut Sawhan (2010) plastik sangat dibutuhkan oleh masyarakat juga mempuyai dampak buruk terhadap lingkungan, plastik bekas sangat potensial mencemari lingkungan karena plastik merupakan bahan sulit terdegradasi sehingga jika di timbun akan memberikan banyak dampak antara lain: (1.) sampah plastik dapat membuat lingkungan tercemar (2.) jika sampah plastik terbakar akan menimbulkan zat-zat yang membahayakan bagi kesehatan dan (3.) apabila jika sampah plastik terdapat di daerah perariran plastik dapat menyumbat aliran air. Plastik dapat bertahan hingga bertahun-tahun sehingga menyebabkan pencemaran terhadap lingkungan. Berdasarkan dampak dari sampah anorganik tersebut, maka dilakukan penelitian untuk mengetahui kepadatan sampah anorganik di ekosistem mangrove Desa Talawaan Bajo, serta menjadi data awal untuk direkomendasikan ke pemerintah setempat dengan tujuan pengelolaan sampah menjadi lebih baik.

\section{METODE PENELITIAN}

Pelaksanaan penelitian dilakukan \pm 2 bulan, Lokasi penelitian dilakukan di ekosistem mangrove pantai Talawaan Bajo. Lokasi penelitian ditampilkan pada Gambar 1.

\section{Metode Pengambilan Sampel}

Sampah laut yang diambil adalah sampah yang terdapat pada tumbuhan mangrove. Berdasarkan tujuan, maka batas pengambilan sampel sampah dibagi menjadi tiga stasiun, dalam satu stasiun terdapat tiga kuadran dengan ukuran $10 \mathrm{x}$ 10. Sampel yang diambil selanjutnya ditimbang dalam satuan gram dan pengolahan data menggunakan perangkat lunak Mc.Exel.

Persamaan yang digunakan untuk mengetahui kepadatan mutlak dan relatif dari potongan dan berat sampah di ekosistem mangrove mengikuti persaman dibawah ini. Coe dan Rogers, (1997) dalam( Walalangi, 2012) :

1. Kepadatan mutlak (Jumlah potongan sampah) = Jumlah potongan sampah dalam tiap kategori Luas Area $\left(\mathrm{m}^{2}\right)$

2. Kepadatan mutlak (berat sampah) $=$ Berat potongan sampah laut dalam tiap kategori Luas Area $\left(\mathrm{m}^{2}\right)$

3. Kepadatan relatif (Jumlah potongan sampah) =

\begin{tabular}{|c|c|}
\hline \multirow{2}{*}{$\mathbf{X} 100$} & Jumlah potongan sampah dalam tiap kategori \\
\hline & $\begin{array}{c}\text { Jumlah total berat potongan sampah dalam semua } \\
\text { kategori }\end{array}$ \\
\hline \multirow[t]{2}{*}{4.} & Kepadatan relatif (berat sampah) $=$ \\
\hline & Berat potongan sampah dalam tiap kategori \\
\hline 10 & $\begin{array}{c}\text { Jumlah total berat potongan sampar } \\
\text { semua kategori }\end{array}$ \\
\hline
\end{tabular}




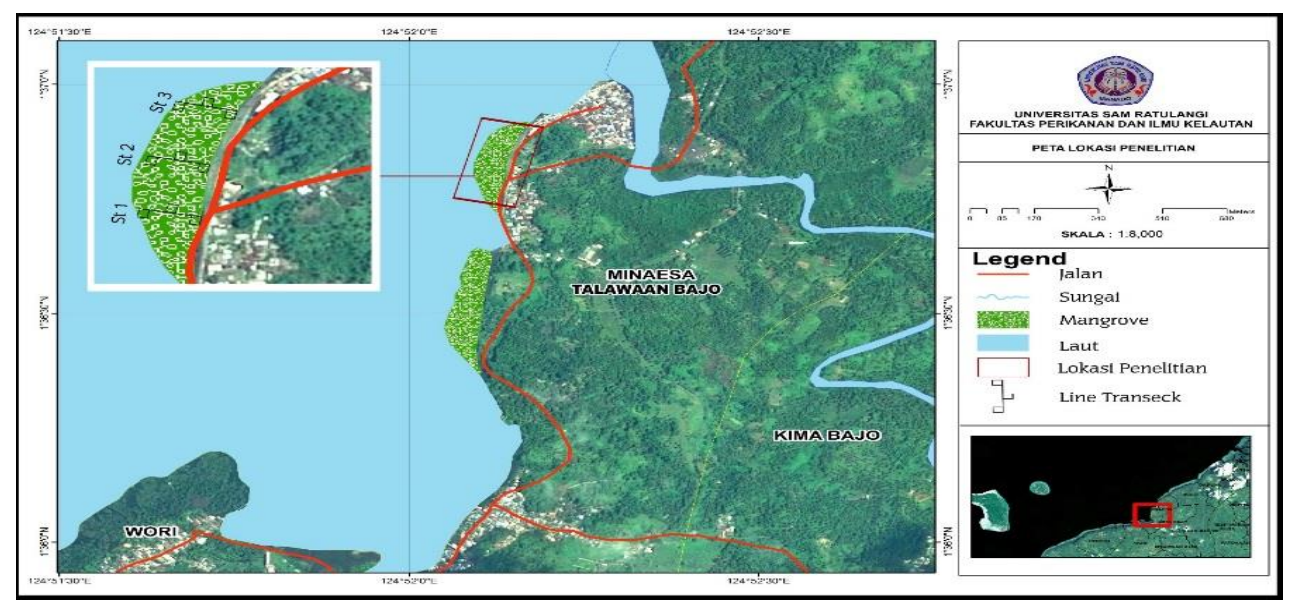

Gambar 1. Peta Lokasi Penelitian

\section{HASIL DAN PEMBAHASAN}

\section{Kondisi Umum Lokasi Penelitian}

Desa Minaesa Talawaan Bajo terletak di Kecamatan Wori, Kabupaten Minahasa Utara, Provinsi Sulawesi Utara. Desa Minaesa Talawaan Bajo dengan luas 918 ha memiliki jumlah penduduk 1.502 jiwa. Sebelah utara berbatasan dengan laut Sulawesi, sebelah timur berbatasan dengan Desa Budo, sebelah selatan berbatasan dengan Desa Kima Bajo, dan sebelah Barat berbatasan dengan laut Sulawesi.

\section{Kondisi Sampah di Ekosistem Mangrove Pantai Talawaan Bajo}

Berdasarkan hasil pengamatan sampel sampah laut yang diperoleh di lokasi penelitian, terdapat 5 kategori jenis sampah laut secara garis besar berdasarkan NOAA (2013) yaitu sampah plastik, logam/metal, karet, kaca, dan kayu. Jumlah, jenis dan berat sampah serta nilai rata - rata yang terdapat di daerah penelitian dapat dilihat tabel 1 dan tabel 2 .

Tabel 1. Total Potongan dan Berat Sampah Laut

\begin{tabular}{|c|c|c|c|c|c|c|c|c|}
\hline \multirow{3}{*}{ Jenis sampah } & \multicolumn{6}{|c|}{ Total Sampah } & \multirow{2}{*}{\multicolumn{2}{|c|}{ Total }} \\
\hline & \multicolumn{2}{|c|}{ Stasiun 1} & \multicolumn{2}{|c|}{ Stasiun 2} & \multicolumn{2}{|c|}{ Stasiun 3} & & \\
\hline & Potongan & Berat $(g)$ & Potongan & Berat $(g)$ & Potongan & Berat $(g)$ & Potongan & Berat $(g)$ \\
\hline Plastik & 40 & 1053,60 & 41 & 1061,35 & 51 & 1016,60 & 132 & 3131,55 \\
\hline karet & 1 & 56,70 & 1 & 103,47 & 2 & 425,43 & 4 & 585,60 \\
\hline logam & 3 & 106,93 & 3 & 151,20 & 4 & 39,95 & 10 & 298,08 \\
\hline kaca & 3 & 204,63 & 1 & 22,09 & 5 & 126,75 & 9 & 353,47 \\
\hline kayu \& Turunan & 4 & 8,72 & 3 & 14,69 & 0 & 0,00 & 7 & 23,41 \\
\hline Total sampah & 51 & 1430,58 & 49 & 1352,80 & 62 & 1608,73 & 162 & 4392,11 \\
\hline
\end{tabular}


Tabel 2. Rata - rata potongan dan berat sampah laut

\begin{tabular}{|c|c|c|c|c|c|c|c|c|}
\hline \multirow{3}{*}{ Jenis sampah } & \multicolumn{6}{|c|}{ Rata - Rata Sampah } & \multirow{2}{*}{\multicolumn{2}{|c|}{ Rata - Rata }} \\
\hline & \multicolumn{2}{|c|}{ Stasiun 1} & \multicolumn{2}{|c|}{ Stasiun 2} & \multicolumn{2}{|c|}{ Stasiun 3} & & \\
\hline & Potongan & Berat $(g)$ & Potongan & Berat $(g)$ & Potongan & Berat (g) & Potongan & Berat $(\mathrm{g})$ \\
\hline Plastik & 40 & 1053.60 & 41 & 1061.35 & 51 & 1016.60 & 44 & 1043.85 \\
\hline karet & 1 & 56,70 & 1 & 46.77 & 2 & 425.43 & 1.33 & 236.10 \\
\hline logam & 3 & 106.93 & 3 & 151.20 & 4 & 39.95 & 3.33 & 99.36 \\
\hline kaca & 3 & 204.63 & 1 & 22.09 & 5 & 126.75 & 3 & 117.82 \\
\hline kayu \& Turunan & 4 & 8.72 & 3 & 14.69 & 0 & 0.00 & 2.34 & 7.80 \\
\hline Rata Rata & 10.2 & 343.47 & 9.8 & 259.22 & 12.4 & 321.75 & 10.80 & 300.99 \\
\hline
\end{tabular}

Nilai sampah anorganik yang dihasilkan dalam penelitian ini dengan jelas dapat dilihat pada tabel 2. Secara Keseluruhan total jumlah potongan sampah adalah 162 pot $/ 900 \mathrm{~m}^{2}(1.800$ $\mathrm{Pot} / \mathrm{Ha})$ dengan berat 4392,11 gram $/ 900 \mathrm{~m}^{2} \quad(48.801,2 \mathrm{gram} / \mathrm{Ha})$, dimana jumlah potongan sampah anorganik terbanyak adalah jenis plastik dengan total $132 \mathrm{pot} / 900 \mathrm{~m}^{2}$ (1.466 Pot/Ha) dengan berat total $3131,55 \quad$ gram $/ 900 \mathrm{~m}^{2} \quad$ (34.795 $\mathrm{Gram} / \mathrm{Ha}$ ) diikuti dengan sampah jenis logam sebanyak 10 pot $/ 900 \mathrm{~m}^{2}(110$ $\mathrm{Pot} / \mathrm{Ha})$ dengan berat 298,08 gram $/ 900 \mathrm{~m}^{2}$ (331,2 gram/ha) jenis kaca sebanyak 9 pot $/ 900 \mathrm{~m}^{2} \quad(100$ $\mathrm{Pot} / \mathrm{Ha}$ ) berat $353,47 \mathrm{gram} / 900 \mathrm{~m}^{2}$
(392,74 gram/ha) sampah jenis kayu. sebanyak 7 pot $/ 900 \mathrm{~m}^{2} \quad(77 \mathrm{Pot} / \mathrm{Ha})$ dengan berat 23,41 (260,11 gram/ha) dan jumlah potongan yang paling sedikit adalah sampah jenis karet berjumlah $4 \mathrm{pot} / 900 \mathrm{~m}^{2}(40 \mathrm{Pot} / \mathrm{Ha})$ dengan total berat $585,60 \mathrm{gram} / 900 \mathrm{~m}^{2}$ $(650,66 \mathrm{gram} / \mathrm{ha})$. Nilai rata - rata (tabel 3) nilai potongan tertinggi sampah jenis plastik yaitu 44 potongan dengan berat 1043, 84833 gram diikuti sampah jenis kayu dan turunan, logam, kaca dan sampah dengan nilai rata - rata paling kecil yaitu jenis karet yaitu 1,33 potongan. Akan tetapi nilai rata - rata berdasarkan berat, nilai yang paling rendah adalah jenis kayu dan turunan yaitu 7,80 gram. 


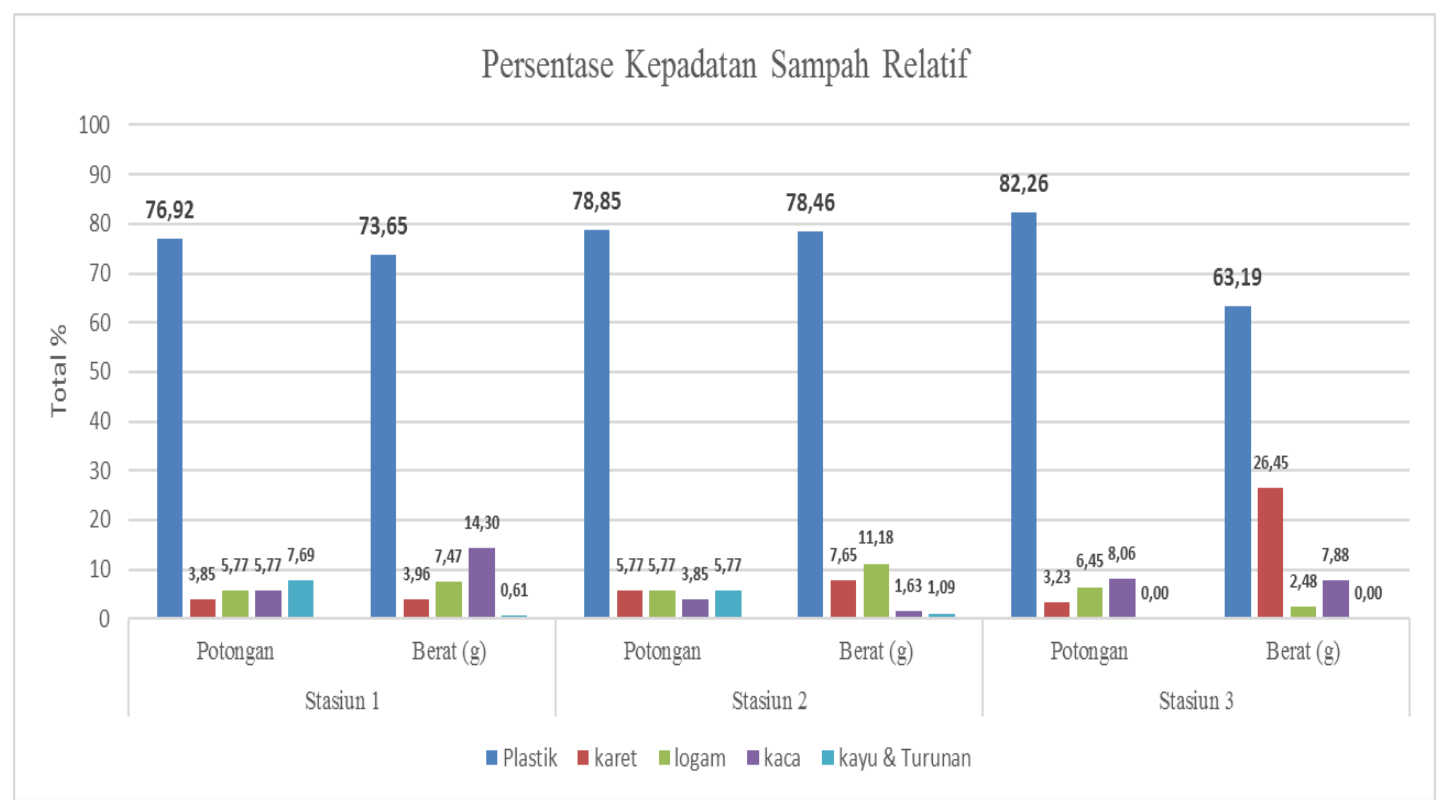

Gambar 3. Persentase kepadatan sampah anorganik relatif tiap stasiun

Berdasarkan gambar 3, sampah anorganik jenis plastik yang dominan dilokasi penelitian. Potongan sampah plastik paling tinggi terdapat pada stasiun 3 yaitu $82,26 \%$ diikuti stasiun $2(73,65 \%)$ dan pada stasiun 1 (76,92\%). Selanjutnya presentase kepadatan sampah anorganik total ditampilkan pada Tabel 3.

Tabel 3. Persentase total kepadatan sampah anorganik di ekosistem mangrove Pantai Talawaan Bajo

\begin{tabular}{|c|l|r|r|}
\hline \multirow{2}{*}{ Peringkat } & \multicolumn{1}{|c|}{ Jenis Sampah } & \multicolumn{2}{|c|}{ Persen ( \% ) } \\
\cline { 3 - 4 } & & Potongan & \multicolumn{1}{c|}{ Berat } \\
\hline 1 & Plastik & 81,48 & 71,3 \\
\hline 2 & Logam & 6,17 & 6,79 \\
\hline 3 & Kaca & 5,56 & 8,05 \\
\hline 4 & Kayu dan Turunan & 4,32 & 0,53 \\
\hline 5 & Karet & 2,47 & 13,3 \\
\hline & Total & 100 & 100 \\
\hline
\end{tabular}

Persentase kepadatan sampah anorganik di ekosistem mangrove pantai Talawaan Bajo adalah sampah jenis plasik yang tertinggi $(81,48 \%)$, diikuti Logam $(6,17 \%)$, Kaca $(5,56 \%)$, kayu dan turunan $(4,32 \%)$ dan yang paling sedikit adalah sampah jenis karet (2,47\%). Berdasasarkan hasil penelitian ini, didukung oleh pernyataan Convention on Biological Diversity; Scientific and Technical Advisory Panel(CBD-STAP) pada tahun 2012 serta hasil penelitian Djaguna tahun 2019 tentang kepadatan sampah di pesisir pantai Talawaan Bajo yang menyatakan plastik merupakan tipe sampah laut dominan.

\section{PENUTUP}

\section{Kesimpulan}

1. Sampah laut anorganik yang teridentifikiasi di lokasi penelitian adalah sampah jenis plastik, karet, logam, kaca, serta kayu dan turunan. Sampah plastik merupakan sampah yang paling banyak di 
temukan pada lokasi, diikuti dengan jenis logam, kaca, kayu dan turunan, serta karet.

2. Kepadatan sampah anorganik di ekosistem mangrove pantai Talawaan Bajo secara keseluruhan adalah 162 pot $/ 900 \mathrm{~m}^{2}$ (1.800 Pot/Ha) dengan berat 4392,11 $\mathrm{gram} / \mathrm{m}^{2}(48.801,2$ gram $/ \mathrm{ha})$, dimana sampah yang paling mendominasi adalah sampah jenis plastik dengan jumlah 132 pot $/ 900 \mathrm{~m}^{2}$ (1.466 Pot/Ha)dengan berat $3131,55 \mathrm{gram} / 900 \mathrm{~m}^{2}$ (34.795 gram.ha) dan sampah yang paling tinggi terdapat pada stasiun 3 yaitu $62 \mathrm{pot} / \mathrm{ha}$ dengan berat $1608,73 \mathrm{gram} / \mathrm{m}^{2}$ (17.874,7 gram $\left./ \mathrm{ha}\right)$.

\section{SARAN}

Berdasarkan hasil penelitian yang dilakukan di ekosistem mangrove pantai Talawaan Bajo, kecamatan Wori, Kabupaten Minahasa Utara, maka disarankan perlu adanya penelitian lanjutan tentang pengaruh sampah anorganik di lingkungan laut. Selain itu banyaknya populasi sampah jenis plastik yang ditemukan dalam penelitian ini dapat menjadi bahan rekomendasi ke pemerintah daerah agar supaya membuat himbauan dan sosialisasi tentang dampak sampah serta edukasi tentang pengelolaan sampah anorganik khusunya jenis plastik ke masyarakat dengan baik.

\section{Ucapan Terima Kasih}

Penulis mengucapkan terima kasih kepada Kemeristek Dikti atas dukungan terhadap kajian ini melalui pelibatan dalam riset terapan dengan ketua peneliti Dr. Joshian N.W. Schaduw, S.IK, M.Si.

\section{DAFTAR PUSTAKA}

Djaguna,A., W.E.Pelle., J.N.W. Schaduw., H.W.K. Manengkey., N.D.C. Rumampuk., E.L.A. Ngangi, 2019. Identifikasi Sampah Laut Di Pantai Tongkaina Dan Talawaan Bajo. Jurnal Pesisir dan Laut Tropis, Fakutas Perikanan dan IImu Kelautan UNSRAT.

NOAA [National Oceanic and Atmospheric Administration]. 2013. Programmatic Environmental Assessment (PEA) for the NOAA Marine Debris Program (MDP). NOAA. Maryland (US).

Sahwan,F.L.,D.H.Martono.,S.Wahyono. ,dan L.A. Wisoyodharmo. 2010, Sistem Pengolahan Limbah Plastik di Indonesia, Jurnal Teknik Lingkungan BPPT, Vol. 6 (1). : 311 $-318$.

Siahainenia. 2001. Pencemaran Laut, Dampak dan Penangulangannya. Makalah Falsafah Sains Program Pasca Sarjana.IPB Bogor.

Walalangi,J.Y.,2012. Analisis Komposisi Sampah Organik Serta Dampak Terhadap Lingkungan Peisisir Kota Palu Sulawesi Tengah. Tesis Institut Pertanian Bogor. 